\title{
ADVANCES IN THE ASSESSMENT OF HOT CRACKING OF CU-CONTAINING STEELS*
}

\author{
Osvaldo Guilherme Comineli ${ }^{1}$ \\ Clodualdo Aranas Jr. ${ }^{2}$ \\ Rian Dippenaar ${ }^{3}$
}

\begin{abstract}
While the hot cracking of Cu-containing steels is a serious and widely known problem for the industry, the literature reports that copper only slightly impairs the hot-ductility measured in laboratory. A distinction is drawn between hot ductility and hot shortness and the respective cracking operating mechanism involved at the respective range of temperature. The representability of the laboratory assessment of hot cracking of $\mathrm{Cu}$ containing steels by hot tensile tests compared with actual results in industrial practice is discussed. The effectiveness of the variable affecting in each cracking mechanism and respective temperature range, focused in improving the hot cracking assessment of $\mathrm{Cu}$-steels and the relative importance of oxidation will also be discussed. It is concluded that the hot tensile test in argon might be a good simulation if properly interpreted and that the role of oxidation is secondary in causing hot shortness. A schematic diagram for the hot tensile test is proposed.
\end{abstract}

Keywords: Cu steels, hot shortness, hot cracking, weathering steels. 


\section{INTRODUCTION}

Copper is a particularly troublesome contaminant since it is not possible to remove it from the molten steel[1] and hence, all the copper entering the furnace will be present in the final alloy. Traditionally, hot shortness has been attributed to the formation of a thin film of liquid, since copper is not oxidized because it is more noble than iron[2]. At hot-working temperatures, iron is removed with the scale, liquid copper concentrates in the external surface and penetrates the steel, surrounding austenite grain boundaries, producing cracks. Consequently, copper content of scrap has to be strictly controlled, thereby limiting the extent to which copper contaminated scrap can be recycled.

Environmental pressures are forcing an increase of use of highly contaminated steel scrap in both in the electric-arc furnace or oxygen processing route.

The susceptibility of steel to crack initiation and growth during the continuous casting of steel is assessed by measuring hot ductility in a tensile test conducted at the temperatures the steel experiences during continuous casting or hot rolling. Hot ductility of steel is usually presented as a curve of reduction in area plotted against the testing temperature and more often than not, a ductility trough is found in the temperature range between the $\mathrm{Ae}_{3}$ and $\mathrm{Ar}_{3}$ temperatures. The loss of ductility in this temperature range is attributed to the formation of a thin film of ferrite on pre-existing austenite grain boundaries[3]. Once this film of ferrite has formed, the stress concentrates in the softer ferrite, leading to crack initiation and propagation along the grain boundaries and eventually to inter-granular fracture. Clearly, the measurement of hot ductility by hot tensile test is relatively easy to conduct, once it is easy to carry on. It provides a reasonable simulation of the high temperature behaviour of steel so it is frequently used to design crack prevention approaches. Hot ductility tests conducted in argon atmosphere show very little impairment of hot-ductility. Mintz et alii[4] reported that copper is only effective in causing impairment $(\sim 20 \% R$ of $A)$ on hot ductility if tests are carried out in partial oxidation and after casting the samples. Although good simulation for general investigation of hot ductility, the test does not correctly predict the influence of copper on the behaviour of steel at hot rolling temperatures. In commercial practice, serious problems with hot shortness is found when steel containing appreciable amounts of copper is hot rolled. The inability of the traditional hot ductility test to predict the behaviour during hot deformation of copper containing steels indicates that crack formation during hot working in such steels is not a conventional problem explained by the hot ductility mechanism. Hence, hot shortness encountered in copper containing steels should be distinguished from decreased hot ductility typically observed in carbon steels; hot shortness results by a different cracking mechanism so the interpretation of the test is also different higher working temperatures.

We contend that hot shortness actually results from the melting of segregated metallic copper at higher temperatures (above $\mathrm{Ae}_{3}$ ) of hot-deformation, causing cracking, but the copper segregation is not consequence of oxidation as it is proposed by the current literature.

Recent works $[5,6]$ proposes a novel approach for the Cu segregation being related to the presence of inclusions which is the principal cause of the hot shortness. The same work reports that within the bulk, copper segregates to MnS inclusions exacerbating the problem of segregation. Copper, either precipitated as sulphides or segregated around MnS inclusions, do not seem to be effective to seriously impair the hot ductility at lower temperatures - between $\mathrm{Ar}_{3}$ and $\mathrm{Ae}_{3}$. However, those 
segregations have important consequences on causing hot cracks, by affecting the hot shortness at temperatures, above $1150^{\circ} \mathrm{C}$. The collapse in reduction of area is promptly detected by the hot tensile test confirming that $\mathrm{Cu}$ in steels is very deleterious for the cracking in that temperature range, as the consequence of a molten Cu containing phase.

Obviously, the best way to simulate the role of copper in causing the hot shortness is by conducting tests is in air, like in the commercial route, so iron will then be oxidized preferentially, thereby increasing the extent of copper segregation. In deep oxidizing atmosphere, it is very difficult to measure to any degree of precision, the ductility at fracture due to excessive oxidation in the fracture area. Consequently, the frequent used technique of determining hot ductility in a hot-tensile test has the limitations with respect to assessing hot shortness, because an inert atmosphere. Hence, in addition to the temperature, other variables like oxidation, CuS precipitates and inclusions ( $\mathrm{Mn}$ and $\mathrm{S}$ content) should be individually investigated concerning their additional effect in the actuating cracking mechanism.

The addition of nickel increases the solubility of copper in the austenite[7] and although nickel additions are expensive, this is traditionally the effective technique used to reduce the hot shortness problem.

On the positive side, the copper that remains dissolved in ferrite, leads to age hardening, an important improvement in mechanical properties, and also improves weathering corrosion resistance[8]. Hence, there is significant commercial interest in capitalizing on the improved properties resulting from copper additions without encountering hot shortness during thermo-mechanical processing.

A distinction is drawn between hot ductility and hot shortness operating mechanisms involved, and the effectiveness of the assessment of the hot shortness will be discussed. It is proposed that hot shortness and hot ductility are very different cracking mechanism, the hot shortness resulting from the melting of previously segregated copper around inclusions and not because of oxidation at higher temperatures of processing of the steel. Alternative ways of assessing hot shortness will be discussed. It is proposed a schematic diagram summarizing the hot tensile test as assessment of the hot cracking concerning mechanisms and variables.

\section{EXPERIMENTAL}

The current exercise compared ductility measured by reduction of area of different compositions of $\mathrm{Cu}$ containing steels submitted to hot tensile tests to failure over a wide temperature range in which 2 different cracking mechanisms are operating. Experiments were carried out in different periods of time, focused in investigating different variables affecting the role of $\mathrm{Cu}$ in producing hot cracks and predict its behave in industrial practice.

Steels basically were tensile tested to failure and reduction of area measured in the fracture. Compositions variated other than $\mathrm{Cu}$, so differences will be discussed when relevant. The composition is given in table 1. 
Table 1: Compositions of the steels investigated (wt\%)

Steel

Si

$\mathrm{Mn}$

$\mathrm{P}$

S

Al

$\mathrm{Cu}$

Other

N

$\begin{array}{cccccccccc}\text { DA0387 } & 0.11 & 0.23 & 0.5 & 0.020 & 0.0018 & 0.043 & 0.48 & 0.005 \mathrm{Ti} & 0.006 \\ \text { DL0096 } & 0.10 & 0.23 & 0.5 & 0.019 & 0.0016 & 0.045 & 0.10 & 0.006 \mathrm{Ti} & 0.006 \\ 2 & 0.21 & 0.14 & 0.9 & 0.025 & 0.0134 & 0.002 & 1.78 & 0.12 \mathrm{Ni} & 0.081 \\ \text { IL0087 } & 0.11 & 1.18 & 0.2 & 0.020 & 0.0065 & 0.031 & - & - & 0.005 \\ \text { IL0088 } & 0.12 & 1.18 & 0.2 & 0.021 & 0.0061 & 0.033 & 0.49 & - & 0.005 \\ \text { IL0089 } & 0.12 & 1.18 & 0.2 & 0.023 & 0.0059 & 0.038 & 0.49 & 0.33 \mathrm{Ni} & 0.004 \\ \text { IL0090 } & 0.12 & 1.18 & 0.2 & 0.021 & 0.0062 & 0.038 & 0.49 & 0.49 \mathrm{Ni} & 0.004\end{array}$

Steels were laboratory vacuum induction cast and forged, except steels 1,2 and 9 which were cast in open air from urban scraps. All samples were heated to $1330^{\circ} \mathrm{C}$ or near to melting temperature, hold for $1 \mathrm{~min}$, cooled to the test temperature and hold for 3 minutes before strained to failure. To investigate influence of carbonitrides or CuS precipitation, cooling rates varied from $25^{\circ} \mathrm{C} / \mathrm{min}$. to $200^{\circ} \mathrm{C} / \mathrm{min}$., so that variable will be discussed. Details concerning the test conditions and microscopy examination will also be discussed when appropriate. Selected areas were submitted to optical \& electronic microscopy (scanning and transition) and Electron Probe Microscopy Analysis (EPMA).

\section{RESULTS}

1 - Hot ductility mechanism - Reduction of area $x$ temperature curves at the temperature range below $\mathrm{Ae}_{3}$

\section{$1 \mathrm{~A}$ - Effect of $\mathrm{Cu}$ in hot ductility of C-Mn steels}

Hot ductility tests have been carried out in a Gleeble machine using $10 \mathrm{~mm}$ diameter and $100 \mathrm{~m}$ long cylindrical samples. Samples were heated up to cast "in situ" with the melt protected by a quartz glass. After casting, the temperature was decreased at the indicated cooling rate, held 3 min followed to strength to break. The hot ductility is measured by the reduction of area considering initial and final diameter.

Following hot tensile tests Scanning electron microscopy (SEM) have been carried out in the fracture and in the longitudinal and section; transmission electron 
microscopy (TEM) using carbon replicas also have been carried out to investigate precipitation.

The original purpose of the exercise was to investigate the role of nickel in preventing hot shortness in copper steels. Figure 1 shows that the addition of $0.5 \% \mathrm{Cu}$ slightly impairs the hot ductility in tests carried out in vacuum. The addition of nickel to the copper containing steels results in full recovery of the deleterious effect of copper. More detailed results will be reported in another work.

file:allcurves

\section{Hot Ductility Curves}

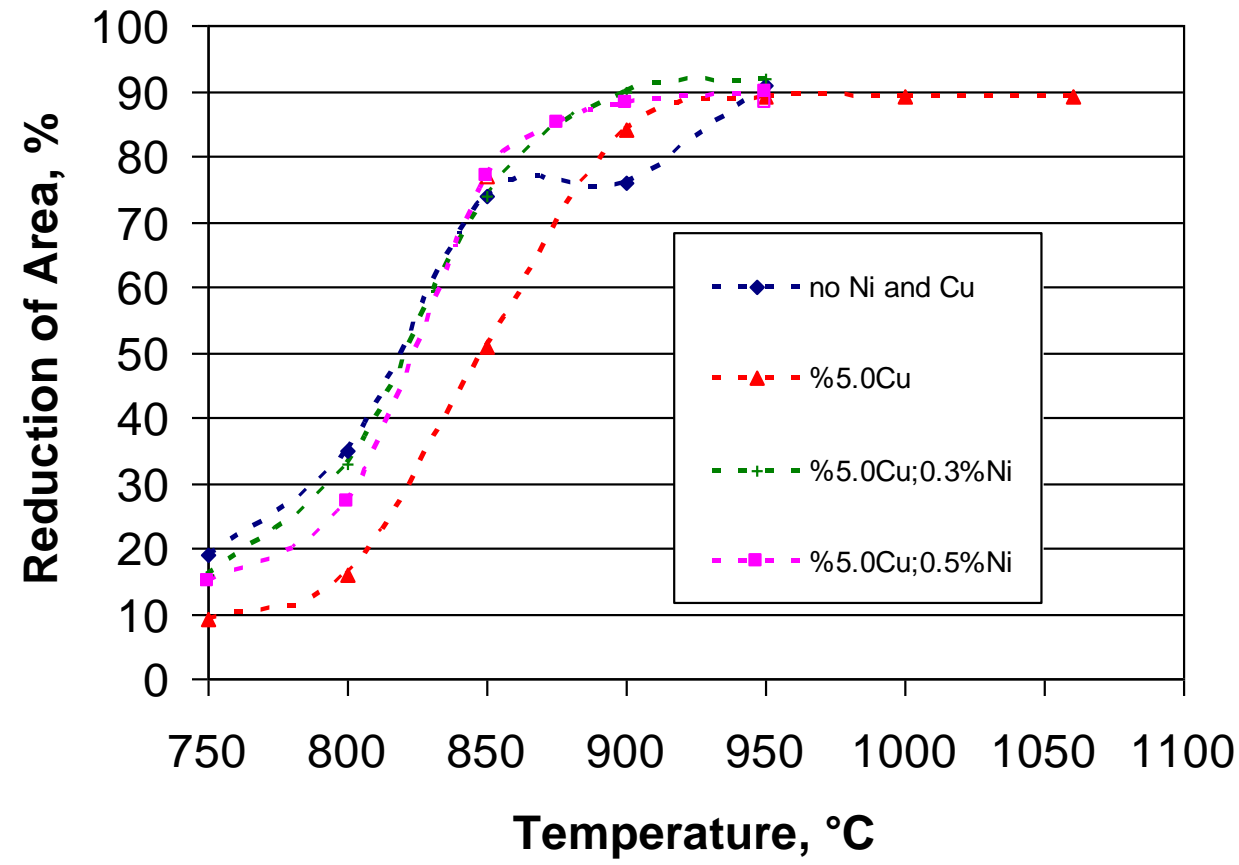

Figure 1- Hot ductility curves for C-Mn-Al as-cast steels, steels IL0087 IL0088 IL0089 IL0090, tested in vacuum at a low cooling rate of $25^{\circ} \mathrm{C} / \mathrm{min}$. Cu additions slightly impair while Ni additions recovers hot ductility[9].

Results also report that addition of $0.5 \% \mathrm{Cu}$ is only deleterious for the hot ductility at slow cooling rate of $25^{\circ} \mathrm{C} / \mathrm{min}$ in the low testing temperature range. No difference was found for the faster cooling rate of $200^{\circ} \mathrm{C} / \mathrm{min}$, as shown in figure 2 . 
File: allcurves.xIx

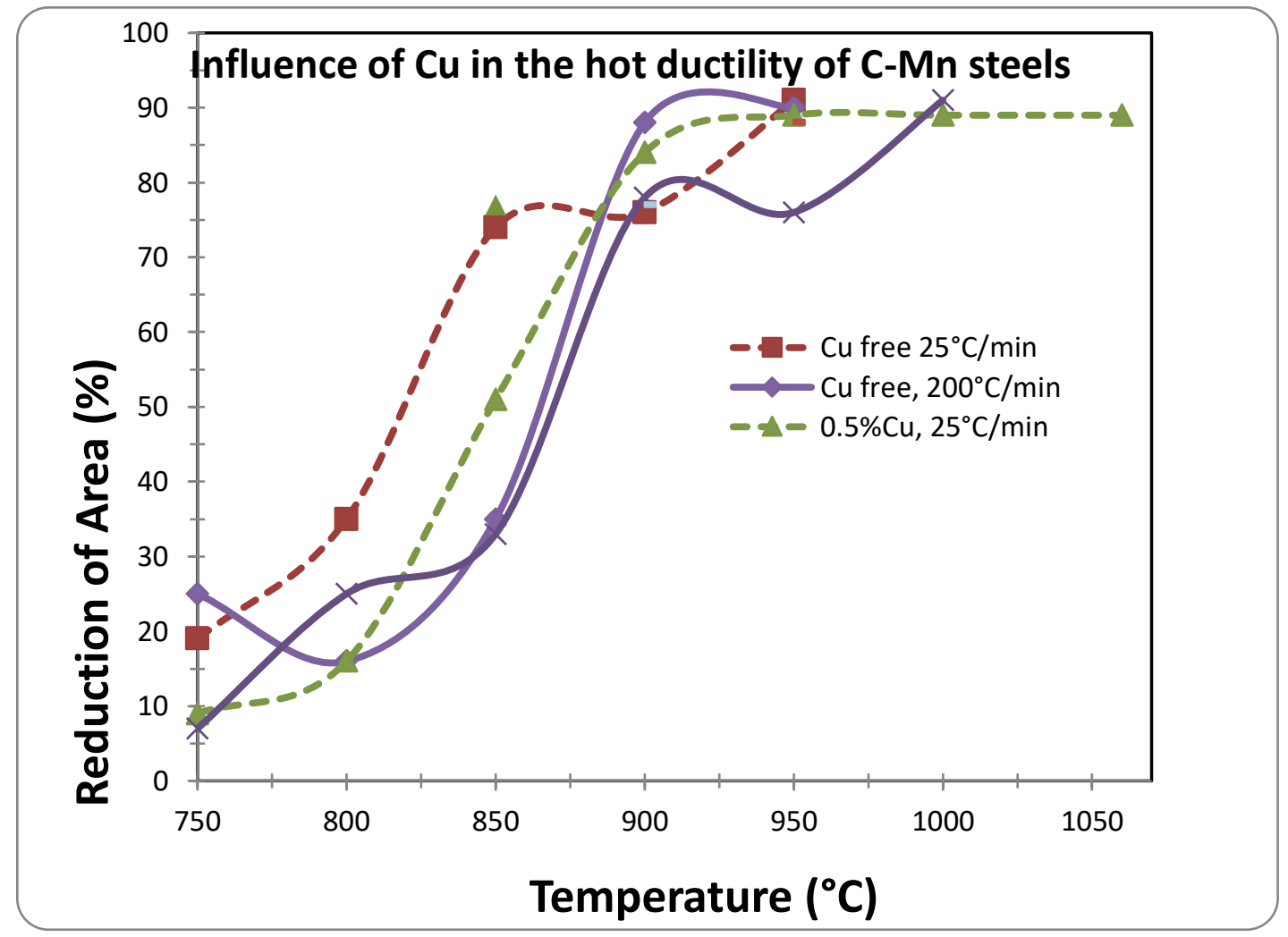

Figure 2 - Hot ductility curves for Cu free (steel IL0087) and 0.5\%Cu (steel IL0088) C- Mn steels tested at different cooling rates. Cu impairment is only at lower cooling rate of $25^{\circ} \mathrm{C}$ because of coarsening precipitates.

Copper segregation of copper around inclusions also have been found also in cross sections of steel containing $0.5 \% \mathrm{Cu}$. Figure 3 shows of copper segregation in $\mathrm{MnS}$ line of inclusions.
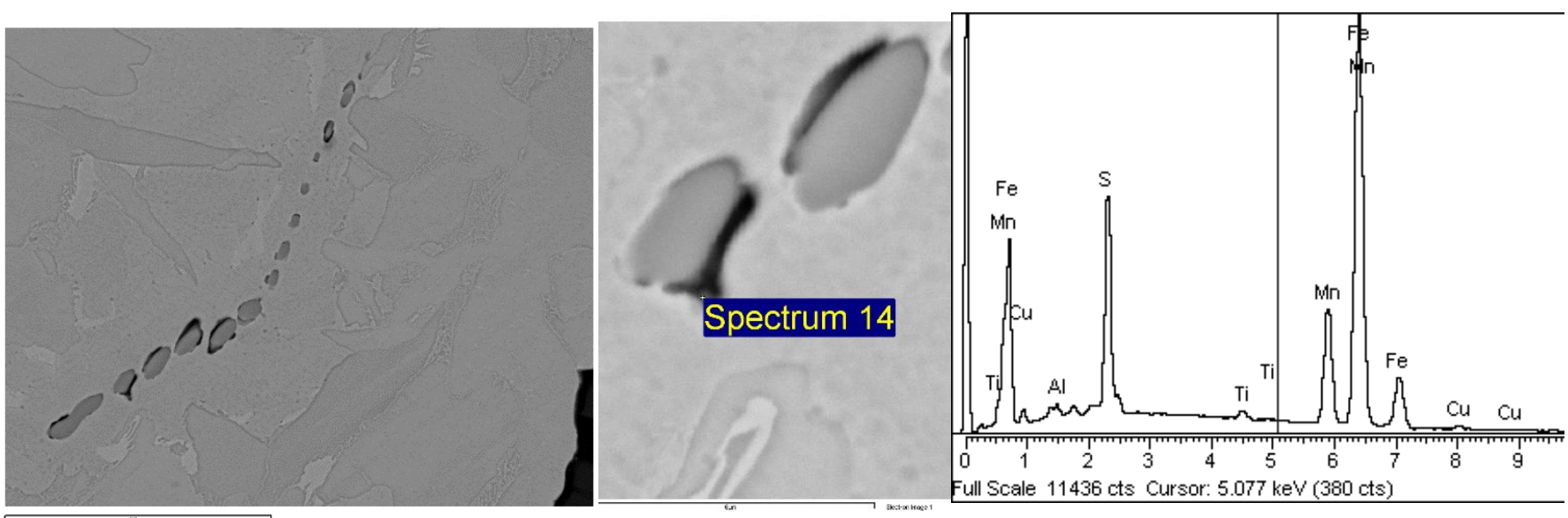

Figure 3 - SEM micrographs of the cross section of the $0.5 \% \mathrm{Cu}$ containing steel. Cooling rate $200^{\circ} \mathrm{C} / \mathrm{min}$, test temperature $800^{\circ} \mathrm{C}$. On the left, a line of MnS inclusions (1000x); centre, enlarged view show details and Cu segregation at the edges of MnS inclusion (5,000x); right, the X-ray spectrum. Reduction in area $25 \%[10]$. 


\section{Cracking associated with $\mathrm{Cu}$}

At higher test temperature, Electron Probe Microscopy Analysis (EPMA) show association between $\mathrm{Cu}$ concentration and crack opened at the border after compressive test carried out in $1.8 \% \mathrm{Cu}$ steel, steel 2, figure 4 . No $\mathrm{Cu}$ segregation were found in the boarder in compressive test. That particularity is might be an important information in supporting the conclusions concerning relative importance of oxidation and role of inclusions in the hot shortness cracking mechanism as will be analysed in the discussion.

File: compression-tip-of-crack-CP.jpg

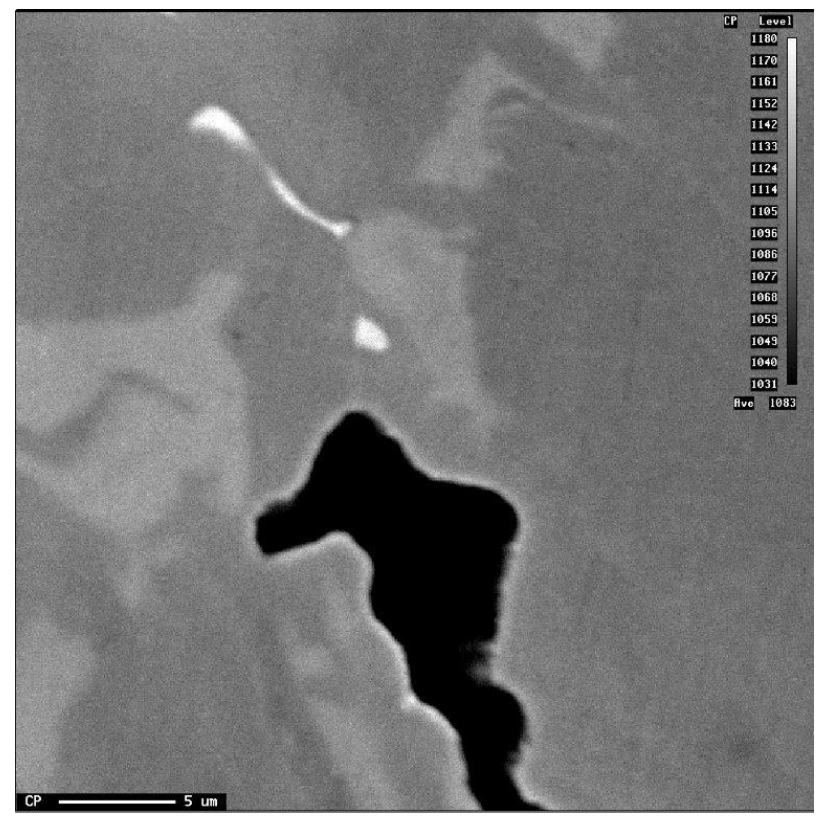

compression-tip-of-crack-CP.jpg

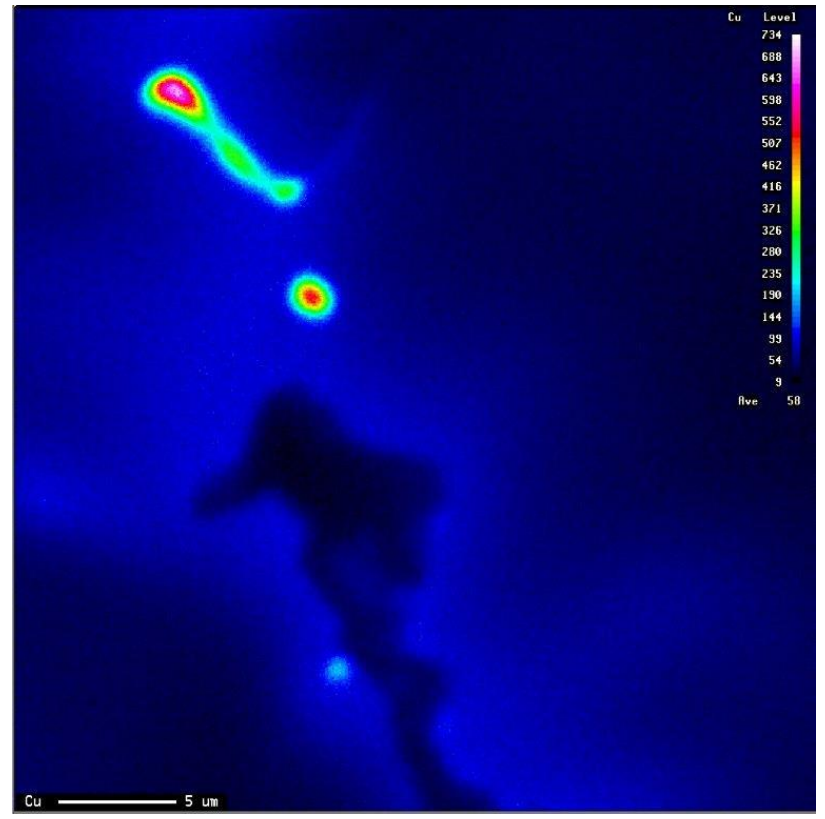

Figure 4 - Electron probe microscopy analysis - EPMA - respective map in the right showing Cu concentration associated with crack open in the edge of compressive test in vacuum of $1.8 \% \mathrm{Cu}$ steel. $1250^{\circ} \mathrm{C}$.

\section{$1 \mathrm{~B}$ - Effect of $\mathrm{Cu}$ in hot ductility of microalloyed steels}

Microalloyed steels tensile tested show the typical mechanism of hot ductility, by producing a trough in curves at temperatures between $\mathrm{Ae}_{3}$ and $\mathrm{Ar}_{3}$, figure 5. Composition influences $\mathrm{Ae}_{3}$ while cooling rate affects $\mathrm{Ar}_{3}$. The depth of the trough is increased by finer precipitation produced by faster cooling rate.

Similarly, like in C-Mn steels, severe $\mathrm{Cu}$ segregations around inclusions have also been found in microalloyed steels. However, an additional impairment of hot ductility is produced by precipitation. TEM investigations have shown that copper also can precipitate as CuS inside the matrix. In the microalloyed steel DA 0387 tested at cooling rate of $100^{\circ} \mathrm{C} / \mathrm{min}$, figure 6 shows presence of coarse CuS, which could be the cause of the small impairment caused by copper observed in C-Mn steels, like observed in figure 1 only at slower cooling rate which is favourable condition for CuS precipitation. 


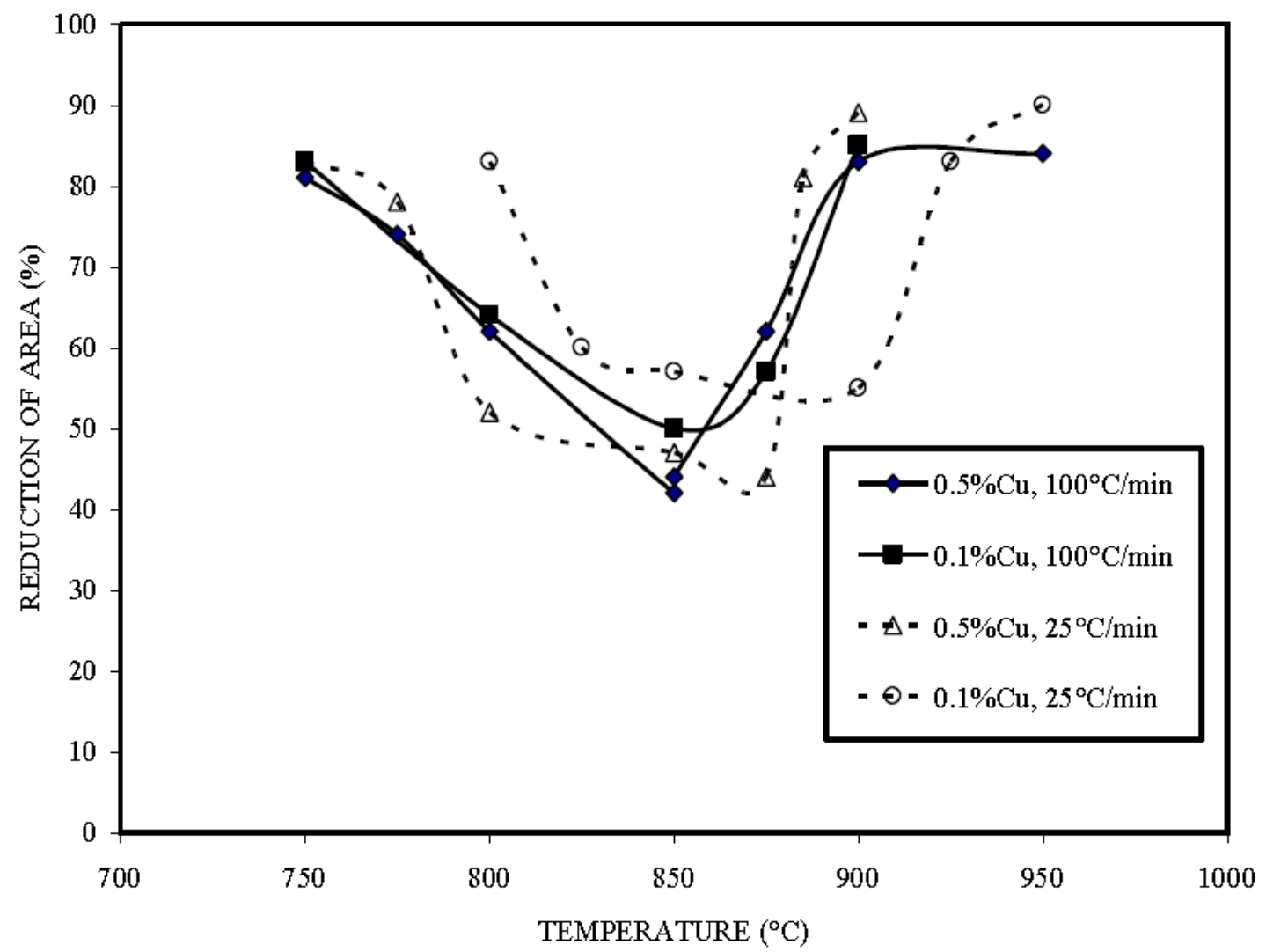

Figure 5 - Hot ductility curves for the Ti microalloyed steels, steels DA0387 and DL0096, investigated for cooling rates of 25 and $100^{\circ} \mathrm{C} / \mathrm{min}[11]$.

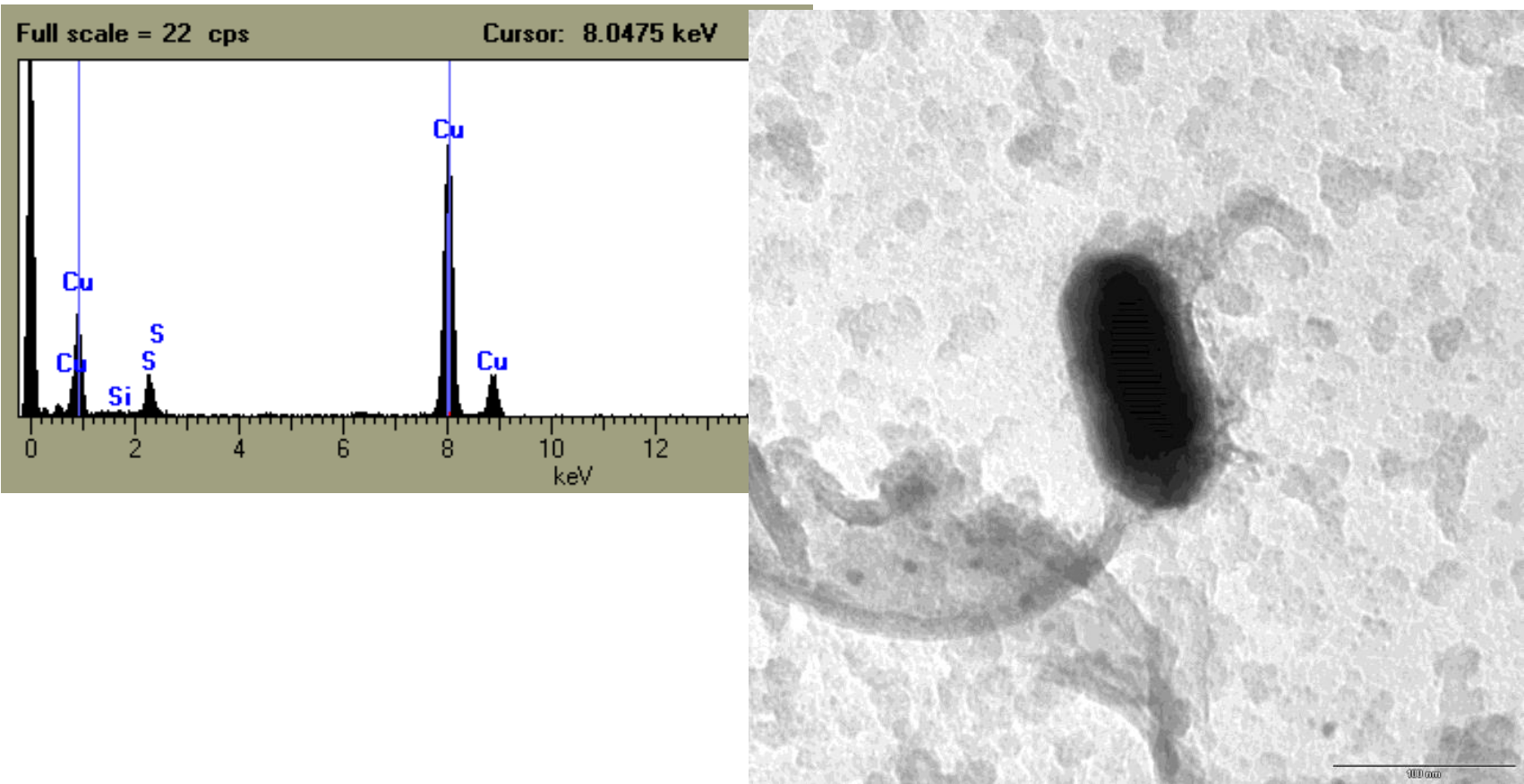

Figure 6 - Coarse CuS precipitate found in $0.5 \% \mathrm{Cu}$ steel, steel DA0387. Cooling rate $100^{\circ} \mathrm{C} / \mathrm{min}$, test temperature $850^{\circ} \mathrm{C}$. CuS precipitate size $\sim 100 \mathrm{~nm}$. 200,000X. Note: Cu grid increases the peak of $\mathrm{Cu}$; it was concluded that the precipitate is CuS because of peak the of S. Reduction in area area 44\% [12]. 
2 - Hot shortness mechanism - Reduction of area $x$ temperature curves at the temperature range above $\mathrm{Ae}_{3}$

\section{Effect of $\mathrm{Cu}$ in the hot shortness mechanism}

Two steels having high $\mathrm{S}$ containing $0.1 \% \mathrm{Cu}$ and $1.8 \% \mathrm{Cu}$ were compared concerning to their behaviour to hot shortness by similar hot tensile tests at temperatures above $\mathrm{Ae}_{3}$ as can be seen in figure 7. Combination of $\mathrm{S}$ and $\mathrm{Cu}$ was very effective in producing impairment in reduction of area once the mechanism of hot shortness is consequence of segregation of $\mathrm{Cu}$ around $\mathrm{MnS}$ inclusions. The liquid phase above $1200^{\circ} \mathrm{C}$ is predicted by thermodynamic calculations (Thermocalc) as show the diagram in figure 8.

File:steel21150-1200C

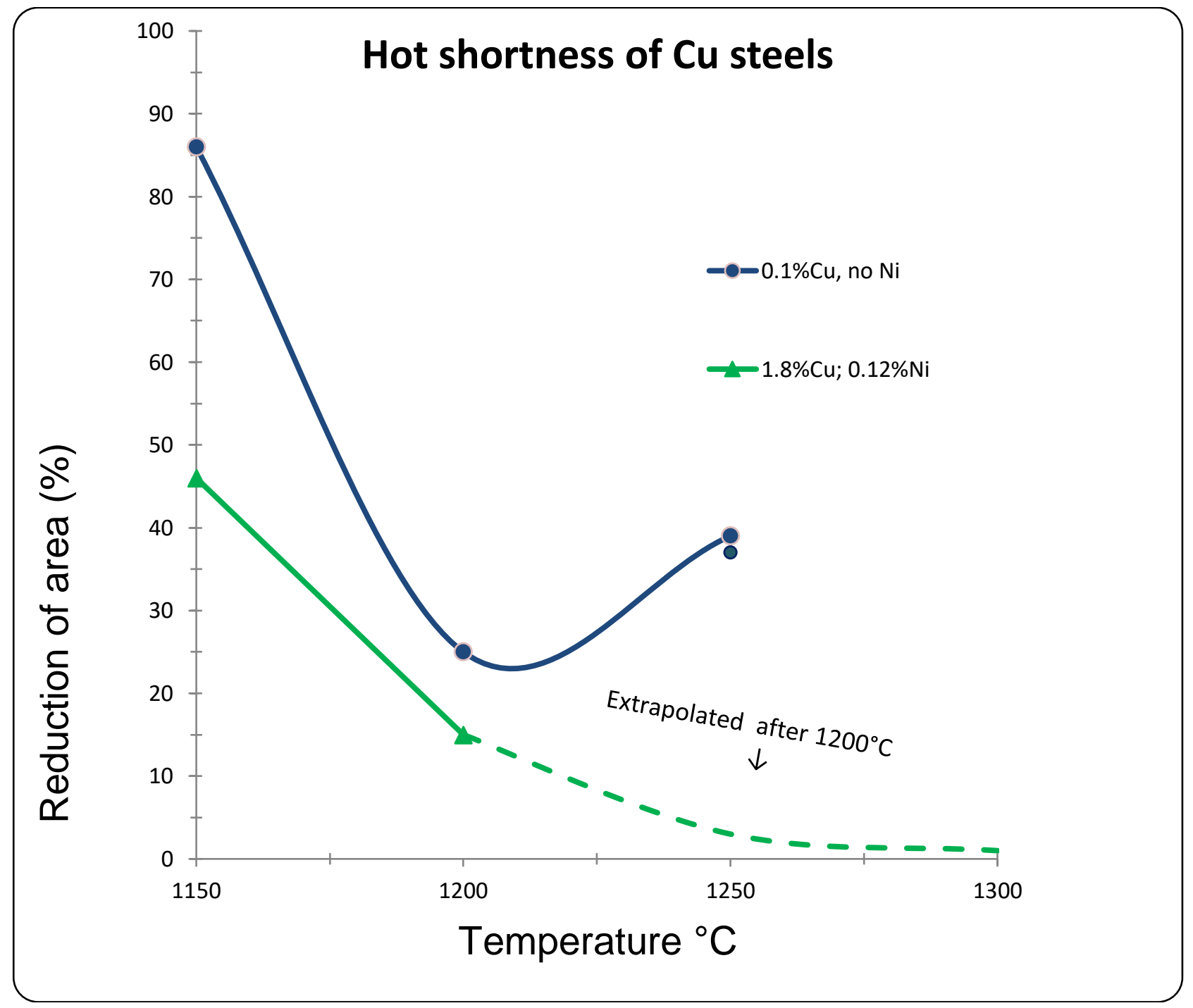

Figure 7 - Comparison of ductility of two Cu-containing steels (steels 1 and 2) in the hot shortness temperature range. $\left(^{*}\right)$ Results above $1200^{\circ} \mathrm{C}$ for high Cu steel are extrapolated because the sample can collapse at temperature in the Gleeble machine due to the increasing amount of liquid. 


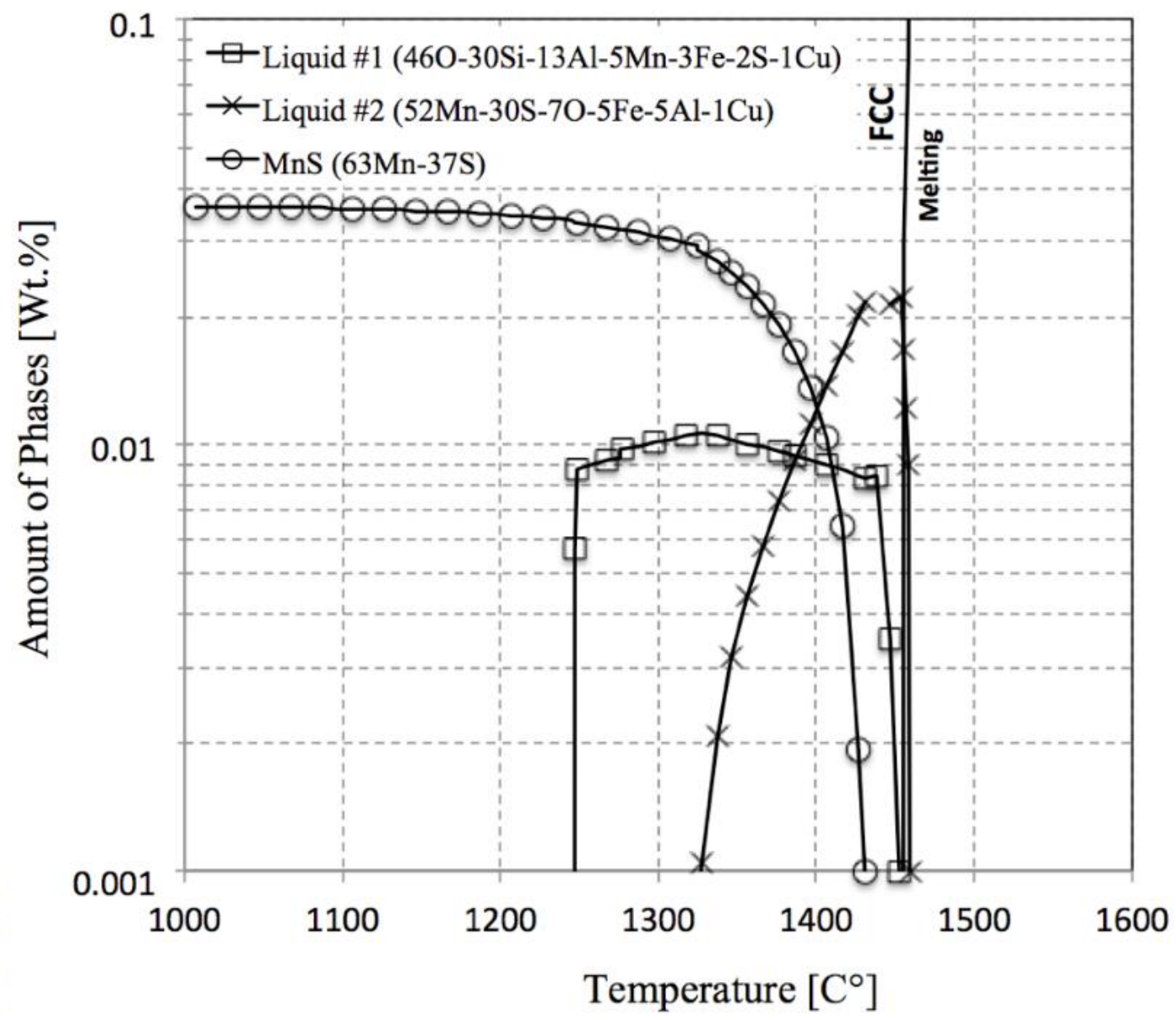

Figure 8 - "Thermocalc" equilibrium diagram matching the occurrence of the liquid in the $1.8 \% \mathrm{Cu}$ steel, steel 2 , at $1250^{\circ} \mathrm{C}$ which is the main cause of the hot shortness.

\section{3 - DISCUSSION}

\section{Simulation of hot ductility and hot shortness}

Hot ductility and hot shortness have very different mechanisms that must to be distinguished in the simulation of the problem and the interpretation of results.

Hot ductility mechanism - ferrite film between austenite grains

Hot ductility tensile testing remains a popular laboratory tool to assess the susceptibility to cracking at the operating temperatures during continuous casting and hot rolling of steel. This approach was also taken in this study and, although there are valid objections to the use of such tests to assess or simulate cracking during continuous casting, it remains one of the best tests for the simulation of crack formation and growth. One of the objections to the validity of such testing is the fact that re-heated specimens are generally evaluated whereas in practice, it is a cast structure that is prone to cracking. In an attempt to make hot tensile testing more industrially relevant, the gauge length of the tensile specimen is often melted and 
resolidified in-situ. The likelihood that cracks will occur during unbending is related to the existence of a ductility trough between the $\mathrm{Ae}_{3}$ and $\mathrm{Ar}_{3}$ temperatures in the hot tensile test. The significant decrease of ductility in this temperature range is attributed to stress and consequently strain concentration in the thin film of ferrite that forms on austenite grain boundaries during cooling from the austenite phase. As a general rule, the width of the trough is determined by the composition of the steel, which affects the $\mathrm{Ae}_{3}$ temperature and the cooling rate, which determines the $\mathrm{Ar}_{3}$ temperature. The depth of the trough is indicative of the presence of precipitates, which exacerbates crack growth that eventually leads to failure. In this respect, fine precipitates are worse than coarse precipitates. The likelihood that a crack will form during the unbending operation in continuous casting is assumed to be low when the hot ductility as measured by the reduction in area, is greater than $40 \%$ [3].

The reduction in area measured in hot tensile tests on samples tested in an argon or vacuum display the classical ductility trough as shown in figure 5 . The experimental evidence why the $0.5 \% \mathrm{Cu}$ steel shows a deeper ductility trough than the copper-free steel CuS precipitation by themselves or copper segregation to MnS may contribute to the reduced ductility in this steel. The simulation of the actual oxidation is another problem, once the scaling on the sample impedes the calculation of the reduction of area. However, like previously reported[5], it is clear in this exercise that oxidation has a secondary role in causing $\mathrm{Cu}$ segregation compared to inclusions. Therefore, results of tests carried out in inert atmospheres are perfectly acceptable, provide it is considered an additional negative contribution by the oxidation. Although there is a suspicious that the role of $\mathrm{Ni}$ is by reducing volume fraction of CuS precipitation, it is not clear either why addition of 0.3 to $0.5 \% \mathrm{Ni}$ to the copper containing steel recovers the hot ductility in samples tested in vacuum. It is then concluded that $\mathrm{Cu}$ is only slightly deleterious in producing cracking in the hot ductility temperature range.

\section{Hot shortness mechanism - liquid film}

The hot shortness is a completely different phenomenon. Traditionally, the explanation is based in the fact that residuals like copper present in steels are nobler than iron so iron is preferably oxidized resulting in built up of copper concentration nearby in surface of the steel. That segregation of copper has lower melting point than the steel, so it can be liquid at the processing temperature. Obviously, that is a condition very favourable for cracking. Once that statement is accepted, it is then clear that oxidizing is an important condition to simulate the problem of hot shortness. However, recent investigations[10,13] show that effects of copper and nickel are not exactly like previously reported[7]. Results to be published[5] show that the problem of hot shortness can be more serious. Copper segregation is produced well before, on solidification. Rather than being homogeneously dissolved in the bulk of the steel, copper segregates surrounding the inclusions present in the steel as shown in figure, 3. That find is very important to understand hot cracking and mechanical properties, since spots of copper segregation are bigger and not only in the surface.

Unfortunately, the hot shortness has been investigation in temperature range out of the hot shortness mechanism. Consequently, the well-known industrial deleterious effect of copper has not been reflected in tests carried out in argon or vacuum, so no useful information can be taken from hot ductility curves. Again, the recovery of the small impairment of hot ductility caused by copper by as shown in the figure 1 cannot explain the important role of nickel in preventing hot cracking. 
In the higher temperature range of hot shortness, the effect of $\mathrm{Cu}$ is much more serious. The copper segregation already present around inclusions plays a decisive role in causing the cracks by forming the liquid film of copper.

Here the effect of nickel in preventing cracks of hot shortness is again completely different from previous work[7].

Once inclusions are accepted as the cause of $\mathrm{Cu}$ segregations rather than oxidation, and the cracking mechanisms are properly interpreted, the assessment of $\mathrm{Cu}$ causing hot cracks is possible by reduction of area in tests carried out in argon vacuum.

Consequently, the hot ductility test remains important to simulate the likelihood of cracking for both $\mathrm{Cu}$ free and $\mathrm{Cu}$ containing steels and oxidization is not a very important variable to be considered.

Similarly, for the hot shortens mechanism the effect of oxidation is also secondary, so the hot tensile test in inert conditions clearly can provide useful information to prevent hot cracks.

The respective mechanisms of hot ductility and hot shortness are summarized in in the generic curve drawn in figure 9 .

File:steel21150-1200C

Effect of $\mathrm{Cu}$ in causing hot cracks in $\mathrm{C}$ steels

(schematic)

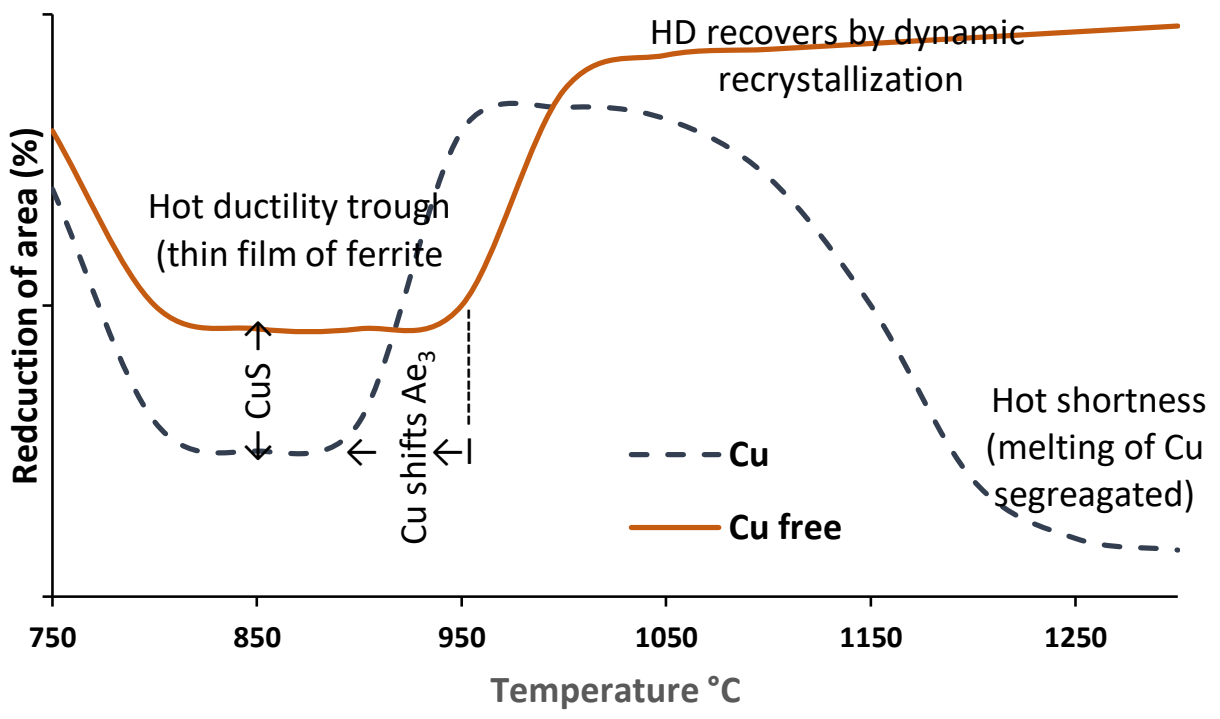

Figure 9 - Proposed schematic diagram summarizing the effect of Cu in causing hot cracks in steels: at lower temperatures $\mathrm{Cu}$ shifts the $\mathrm{Ae}_{3}$ to lower temperatures and increases the depth of the trough by CuS precipitation; at higher temperatures, the impairment is due to $\mathrm{Cu}$ containing liquid $\mathrm{Cu}$ segregated around inclusions.

Alternatively, the cracking assessment of occurrence of liquid copper in causing the mechanism of hot shortness could be detected by a simple hot test carried out in air without any strain, followed by microscopy analysis. Another easier, simpler and useful information for a closer simulation of the hot rolling process of $\mathrm{Cu}$ steels could be taken from quantitative measurement of cracks in hot compressive test carried out in air. Attention must be paid on the fact that hot compressive test does not produce Cu segregation in the edge of the sample like in hot tensile test.

Cleaning the steel, which means reducing sulphur and manganese is the most effective engineering action to reduce hot shortness. In absence of the coarse 
segregation sites of $\mathrm{MnS}$ inclusions, $\mathrm{Cu}$ will be dissolved in ferrite which is also interesting for age hardening of the steel. A patent in this novel theory is deposited[14].

\section{4 - CONCLUSIONS}

Clearly assessing the likelihood of crack in hot processing of steels by hot tensile test, hot ductility and hot shortness should be distinguished. Those cracking mechanisms are very different, so they must be distinguished in the interpretation of results in order to increase the confidence of hot tensile test in preventing hot cracks. Some conclusions can then be taken from the current work:

1 - The segregation of copper surrounding inclusions is very important and cannot be ignored in investigating the hot shortness. It can be taken from SEM-EDX microscopic analysis after hot tensile test of the steel;

2 - Reduction of area measured from the hot ductility tensile test can be a good orientation in the prevention of the hot shortness in Cu containing steels provide the cracking mechanism is identified. Casting the sample is important but not mandatory. An impairment of about $20 \% R$ of $A$ is estimated to be added to the ductility as result of oxidation once that variable cannot be simulated;

3 - Addition of nickel is effective in preventing the hot shortness. However, attention must be taken on its various role in recovering the ductility in the hot tensile test. Between $\mathrm{Ae}_{3}$ and $\mathrm{Ar}_{3}$ temperatures, $\mathrm{Ni}$ reduces $\mathrm{CuS}$ precipitation. At higher temperatures $\mathrm{Ni}$ increase the solubility of $\mathrm{Cu}$, reduce and modify the inclusions. At the surface and under oxidation, $\mathrm{Ni}$ delays the cracking by producing an alloy of higher melting point with copper. The role of nickel need further investigations.

4 - Cleaning $S$ in the steel is the most effective way to reduce hot shortness so $\mathrm{Mn}$ addition can be reduced. MnS inclusions are naturally coarse and produces more $\mathrm{Cu}$ segregation. In absence of inclusions, $\mathrm{Cu}$ will be dispersed in ferrite which is interesting for improving mechanical properties by age hardening;

5 - Hot compressive test carried out in air could be an easier and cheaper alternative for the assessment of the hot shortness. That is to be further investigated by authors.

\section{ACKNOWLEDGEMENTS}

Authors gratefully thank USIMINAS Steel and Fundição Tecnosteel (Brazil) for supplying the steels and Mr. Seppo Järvenpää and Mr. Juha Uusitalo from the University of Oulu for their laboratory assistance. Birks Emeritus Professor J. J. Jonas from McGill University and Pentti Karjalainen from University of Oulu are also thanked for the valuable discussion and comments. O. Comineli thanks CAPES, the Brazilian Research Agency, for the financial support.

\section{REFERENCES}

[1] A.J. Hartley, P. Eastburn and N. Leece, Steelworks Control of Residuals, Philosophical Transactions A 295(1413) (1980) 45-55.

[2] D.A. Melford, The influence of residual and trace elements on hot shortness and high temperature embrittlement, Philosophical Transactions A 295(1413) (1980) 89-103. 
[3] B. Mintz, S. Yue and J.J. Jonas, Hot ductility of steels and its relationship to the problem of transverse cracking during continuous-casting., International Materials Reviews 36(5) (1991) 187-217.

[4] B. Mintz, R. Abushosha and D.N. Crowther, Influence of small additions of copper and nickel on hot ductility of steels, Materials Science and Technology 11(5) (1995) 474-481.

[5] O. Comineli, Investigations on the influence of oxidation in causing hot cracking in steels, Termo-Mechanical Simulation and Processing of Steels SimPro, Ranchi, India, 2016, p. 10.

[6] O. Comineli, T. Juuti and C.A. Jr, The importance of MnS inclusions on the hot shortness of Cu-containing steels., Steel Research International (2017).

[7] G.L. Fisher, The effect of nickel on the high-temperature oxidation characteristics of copper-bearing steels, Journal of The Iron and Steel Institute 7 (1969) 1010-1016.

[8] S. Vaynman, M.E. Fine and S.P. Bhat, High Strength Copper Steel for Rail Tank Cars to Bridges, Copper Applications in Metallurgy of Copper and Copper Alloys, 2006, 2006.

[9] B. Mintz, O. Comineli and L.P. Karjalainen, The Influence of $\mathrm{Ni}$ on the Hot Ductility of C-Mn-Al, Cu Containing Steels as a Way of preventing "Hot Shortness". 59 $9^{\text {th }}$ Annual Conference of Associacao Brasileira de Metalurgia e Materiais, 2004, São Paulo. São Paulo, Sao Paulo, SP, Brazil, 2004, pp. 18851891.

[10] J.C. Jardim, O. Comineli and R. Dippenaar, Investigations on the Influence of Nickel on the "HOT SHORTNESS" of C-Mn-Al, Cu containing steels., ABM - 45 ${ }^{\text {th }}$ Rolling Seminar, 21 a 24 de outubro de 2008, Porto de Galinhas, Recife, PE; 10/2008, Porto de Galinhas, Recife, PE; Brazil, 2008.

[11] O. Comineli, B. Mintz and L.P. Karjalainen, The influence of cooling rate on the hot ductility of $\mathrm{Cu}$ containing steels, $37^{\text {th }}$ Steelmaking Seminar Associação Brasileira de Metalurgia e Materiais, Porto Alegre, RS, Brazil, 2006, pp. 426-436.

[12] O. Comineli, A. Tuling, B. Mintz and L.P. Karjalainen, The influence of a small $\mathrm{Ti}$ addition on the HOT DUCTILITY of $\mathrm{Cu}$ containing steels, $62^{\text {nd }}$ International Congress of the ABM, July 23-27 2007, Vitória - ES, Vitória - ES - Brazil, 2007, pp. 3085-3094.

[13] O. Comineli, L.P. Karjalainen and R. Dipenaar, The influence of inclusions on the "HOT SHORTNESS" of $\mathrm{Cu}$ containing steels., 62 ${ }^{\text {nd }}$ International Congress of the ABM, Vitoria, ES, Brazil, 2007, pp. 3095-3106.

[14] O.G. Comineli, O. Guilherme Comineli, New Technology for the manufacture of high-copper, low-manganese weathering grade steel with technological, economic and environmental advantages., in: INPI, WIPO/PCT (Eds.) Universidade Federal Do Espirito Santo-UFES, Brazil, 2010. 